\title{
Chaos Control on a Duopoly Game with Homogeneous Strategy
}

\author{
Manying Bai and Yazhou Gao \\ Department of Finance, Beihang University, Beijing 100191, China \\ Correspondence should be addressed to Manying Bai; baimy@buaa.edu.cn \\ Received 19 April 2016; Accepted 14 June 2016 \\ Academic Editor: Christos K. Volos
}

Copyright ( 2016 M. Bai and Y. Gao. This is an open access article distributed under the Creative Commons Attribution License, which permits unrestricted use, distribution, and reproduction in any medium, provided the original work is properly cited.

\begin{abstract}
We study the dynamics of a nonlinear discrete-time duopoly game, where the players have homogenous knowledge on the market demand and decide their outputs based on adaptive expectation. The Nash equilibrium and its local stability are investigated. The numerical simulation results show that the model may exhibit chaotic phenomena. Quasiperiodicity is also found by setting the parameters at specific values. The system can be stabilized to a stable state by using delayed feedback control method. The discussion of control strategy shows that the effect of both firms taking control method is better than that of single firm taking control method.
\end{abstract}

\section{Introduction}

An oligopoly is a market form in which a market or industry is dominated by a small number of sellers. Thus, they have power to decide the market price and the yields. The behavior of one player inevitable influences the other players' behavior. To maximize their profits, each oligopolist is likely to be aware of the actions of the others.

Cournot, in 1838, introduced the first formal theory of oligopoly [1]. In Cournot model, each oligopolist assumes that other firms hold their outputs constant, and all oligopolists select a quantity based on others' outputs to maximize profits. However, oligopoly game becomes complex when the players adopt dynamic strategy depending on their previous outputs and their rivals' outputs.

Expectations play an important role in modeling economic phenomena. A firm can choose its expectation rules to adjust its production. There exist three different firms' expectations: naive, bounded rational, and adaptive [2]. The case of where both players adopt bounded rational expectation and that of one takes bounded rational expectation and the other takes adaptive expectation have been studied by many researchers [3-10]. However, there are few literatures that focus on the case of where both players adopt adaptive expectation.

Recently, the dynamics of duopoly game has been studied by many researchers. Chaotic phenomena in duopoly game were first found by Puu [11]. Later, Kopel [12] studied the stability of the duopoly game with different demand functions and different cost functions. Chaos was also found in this paper. Agiza and Elsadany [2] studied the dynamics in the Cournot duopoly game with heterogeneous players; in which case, one player accepts naive expectation, and the other adopts bounded rational expectation. Ma and Ji [4] studied duopoly game with homogenous players in electric power industry, where both players adjust their outputs according to bounded rational rule. Sarafopoulos [5] assumed that one player accepts bounded rational expectation and the other uses adaptive expectation.

Since chaotic phenomena were found in duopoly game, there are also many researchers focusing on the chaos control in duopoly game [6, 13-17]. However, to our best knowledge, there are few literatures that focus on the efficiency of chaos control. In this paper, we explore the dynamics of a homogeneous duopoly game where both players take adaptive expectation. According to the analysis of numerical simulations, the parameters' effects on the stability of the system are obtained. To lead the system to stable state, we try to use DFC method. The efficiency of the case where only one company takes control measure and that of the case where both companies take control measure is compared.

The paper is organized as follows. In Section 2, the model and the parameters are introduced. In Section 3, we study the equilibriums and the stability of the equilibriums of the model. In Section 4, we give the numerical results about the reactions of the two players. In Section 5, we control the system to a stable situation. Section 6 gives the conclusions. 


\section{The Model}

We assume that the duopoly players produce homogenous goods which are perfect substitutes and offer goods at discrete-time periods. Therefore, the duopoly players face the same market demands. They both choose adaptive expectation rule to decide the amounts of the goods in the next period as their response strategy. Assume that the total demand is reciprocal to price $p$; therefore, the reverse demand function is

$$
p=\frac{1}{q_{1}+q_{2}},
$$

where $q_{i}(i=1,2)$ represents the quantity that firm $i$ produced. The cost of firm $i$ contains two parts: one is constant cost $d_{i}$ and the other is variable cost. The per units cost corresponding to the variable cost is constant, and the value is $c_{i}$. Then, the total cost of firm $i$ is

$$
C_{i}\left(q_{i}\right)=c_{i} q_{i}+d_{i}
$$

Now, we present a simple case which will be used to modify players' expectation latter. In this case, both firms have the conception that the other firm will produce at time $t+1$ as it did at time $t$. Then, they will decide their outputs based on the amounts their rival player did at time $t$. Then, the expectation net profits of firm 1 and firm 2 at time $t+1$ can be expressed as

$$
\begin{aligned}
\pi_{1} & =p * q_{1}-C_{1}\left(q_{1}\right) \\
& =\frac{q_{1}(t+1)}{q_{1}(t+1)+q_{2}(t)}-c_{1} q_{1}(t+1)-d_{1}, \\
\pi_{2} & =p * q_{2}-C_{2}\left(q_{2}\right) \\
& =\frac{q_{2}(t+2)}{q_{1}(t)+q_{2}(t+1)}-c_{2} q_{2}(t+1)-d_{2} .
\end{aligned}
$$

The marginal expectation profits of firm 1 and firm 2 at $\left(q_{1}, q_{2}\right)$ are as follows:

$$
\begin{aligned}
& \frac{\partial \pi_{1}}{\partial q_{1}}=\frac{q_{2}(t)}{\left(q_{1}(t+1)+q_{2}(t)\right)^{2}}-c_{1}, \\
& \frac{\partial \pi_{2}}{\partial q_{2}}=\frac{q_{1}(t)}{\left(q_{1}(t)+q_{2}(t+1)\right)^{2}}-c_{2} .
\end{aligned}
$$

The firms can make maximize profits when the marginal profits are zero. Then, the reaction outputs of the two firms with respect to their competitor's last outputs are

$$
\begin{aligned}
& q_{1}(t+1)=q_{1}\left(q_{2}\right)=\sqrt{\frac{q_{2}(t)}{c_{1}}}-q_{2}(t), \\
& q_{2}(t+1)=q_{2}\left(q_{1}\right)=\sqrt{\frac{q_{1}(t)}{c_{2}}}-q_{1}(t) .
\end{aligned}
$$

In order to make sure that $q_{i}(i=1,2)$ is nonnegative, the reaction functions are modified as

$$
\begin{aligned}
& q_{1}(t+1)= \begin{cases}\sqrt{\frac{q_{2}}{c_{1}}}-q_{2}, & 0<q_{2} \leq \frac{1}{c_{1}}, \\
0, & q_{2}>\frac{1}{c_{1}},\end{cases} \\
& q_{2}(t+1)= \begin{cases}\sqrt{\frac{q_{1}}{c_{2}}}-q_{1}, & 0<q_{1} \leq \frac{1}{c_{2}}, \\
0, & q_{1}>\frac{1}{c_{2}} .\end{cases}
\end{aligned}
$$

On the condition that the two firms have adaptive expectation, the firms compute their outputs with weights between their own last outputs and their reaction outputs $q_{i}\left(q_{j}\right)(i \neq$ $j)$. Then, the outputs they produce in the next period are as follows:

$$
\begin{aligned}
& q_{1}(t+1)=\left(1-v_{1}\right) * q_{1}(t)+v_{1} * q_{1}\left(q_{2}\right), \\
& q_{2}(t+1)=\left(1-v_{2}\right) * q_{2}(t)+v_{2} * q_{2}\left(q_{1}\right),
\end{aligned}
$$

where $q_{1}\left(q_{2}\right)$ and $q_{2}\left(q_{1}\right)$ are as (6) and (7), respectively, and $v_{1}$ and $v_{2}$ are weights on firms' reaction outputs, respectively. We focus on the dynamics of system (8) in the next section.

\section{Equilibrium and Stability}

By setting $q_{i}(t+1)=q_{i}(t),(i=1,2)$ in map (8), the equilibrium output points of the dynamic duopoly game can be obtained as the nonnegative solutions of the algebraic system:

$$
\begin{aligned}
& -q_{1}(t)+\sqrt{\frac{q_{2}(t)}{c_{1}}}-q_{2}(t)=0, \\
& -q_{2}(t)+\sqrt{\frac{q_{1}(t)}{c_{2}}}-q_{1}(t)=0 .
\end{aligned}
$$

The system has two equilibriums: one is $E_{1}^{*}(0,0)$ and the other is $E_{2}^{*}\left(q_{1}^{*}, q_{2}^{*}\right)=\left(c_{2} /\left(c_{1}+c_{2}\right)^{2}, c_{1} /\left(c_{1}+c_{2}\right)^{2}\right) . E_{1}^{*}$ has no practical significance because both the outputs of two firms are zero. Hence, we just investigate Nash equilibrium $E_{2}^{*}$.

The Jacobian matrix of the two-dimensional map (8) at equilibrium $E_{2}^{*}$ is

$$
J(E)=\left[\begin{array}{cc}
1-v_{1} & \frac{1}{2} v_{1} \sqrt{\frac{1}{c_{1} q_{2}^{*}}}-1 \\
\frac{1}{2} v_{2} \sqrt{\frac{1}{c_{2} q_{1}^{*}}}-1 & 1-v_{2}
\end{array}\right] .
$$

According to Agiza and Elsadany [3], equilibrium $E_{2}^{*}$ is locally stable if the following conditions are held:

$$
\begin{array}{r}
1-T+D>0, \\
1+T+D>0, \\
1-D>0,
\end{array}
$$


where

$$
\begin{aligned}
T= & 2-v_{1}-v_{2}, \\
D= & v_{1} v_{2}-v_{1}-v_{2}-\frac{1}{4} v_{1} v_{2} \sqrt{\frac{1}{c_{1} q_{2}^{*} c_{2} q_{1}^{*}}}+\frac{1}{2} v_{1} \sqrt{\frac{1}{c_{1} q_{1}^{*}}} \\
& +\frac{1}{2} v_{2} \sqrt{\frac{1}{c_{2} q_{1}^{*}}} \\
= & v_{1} v_{2}-v_{1}-v_{2}-\frac{1}{4} \frac{v_{1} v_{2}\left(c_{1}+c_{2}\right)^{2}}{c_{1} c_{2}}+\frac{1}{2} \frac{v_{1}\left(c_{1}+c_{2}\right)}{c_{1}} \\
& +\frac{1}{2} \frac{v_{2}\left(c_{1}+c_{2}\right)}{c_{2}} .
\end{aligned}
$$

By substituting $T$ and $D$ into (11), the stable conditions of equilibrium $E_{2}^{*}$ become

$$
\begin{aligned}
& 2\left(c_{1}+c_{2}\right)\left(v_{1} c_{2}+v_{2} c_{1}\right)-v_{1} v_{2}\left(c_{1}-c_{2}\right)^{2}-4 c_{1} c_{2}>0, \\
& 2\left(c_{1}+c_{2}\right)\left(v_{1} c_{2}+v_{2} c_{1}\right)-v_{1} v_{2}\left(c_{1}-c_{2}\right)^{2} \\
& \quad-8 c_{1} c_{2}\left(v_{1}+v_{2}\right)+12 c_{1} c_{2}>0, \\
& -2\left(c_{1}+c_{2}\right)\left(v_{1} c_{2}+v_{2} c_{1}\right)+v_{1} v_{2}\left(c_{1}-c_{2}\right)^{2} \\
& \quad+4 c_{1} c_{2}\left(v_{1}+v_{2}+1\right)>0 .
\end{aligned}
$$

In view of (10), the eigenvalues associated with the equilibrium $E_{2}^{*}\left(q_{1}^{*}, q_{2}^{*}\right)$ are

$$
\begin{aligned}
& \lambda_{1}=\frac{T+\sqrt{T^{2}-4 D}}{2}, \\
& \lambda_{2}=\frac{T-\sqrt{T^{2}-4 D}}{2} .
\end{aligned}
$$

Now, suppose that

$$
\begin{aligned}
T^{2}-4 D & <0, \\
\left|\lambda_{i}\right| & =1, \quad i=1,2 .
\end{aligned}
$$

Then, $D=1$; namely,

$$
\begin{aligned}
v_{1} v_{2}- & v_{1}-v_{2}-\frac{1}{4} \frac{v_{1} v_{2}\left(c_{1}+c_{2}\right)^{2}}{c_{1} c_{2}}+\frac{1}{2} \frac{v_{1}\left(c_{1}+c_{2}\right)}{c_{1}} \\
+ & \frac{1}{2} \frac{v_{2}\left(c_{1}+c_{2}\right)}{c_{2}}=1 .
\end{aligned}
$$

It follows from (16) that

$$
v_{1}=\frac{1+v_{2}-v_{2}\left(c_{1}+c_{2}\right) / 2 c_{2}}{v_{2}-1-v_{2}\left(c_{1}+c_{2}\right)^{2} / 4 c_{2}+\left(c_{1}+c_{2}\right) / 2 c_{2}}=v_{1}^{*} \text {. }
$$

Then, $\left(q_{1}^{*}, q_{2}^{*}, v_{1}^{*}\right)$ is a candidate for Neimark-Sacker bifurcation point [18].

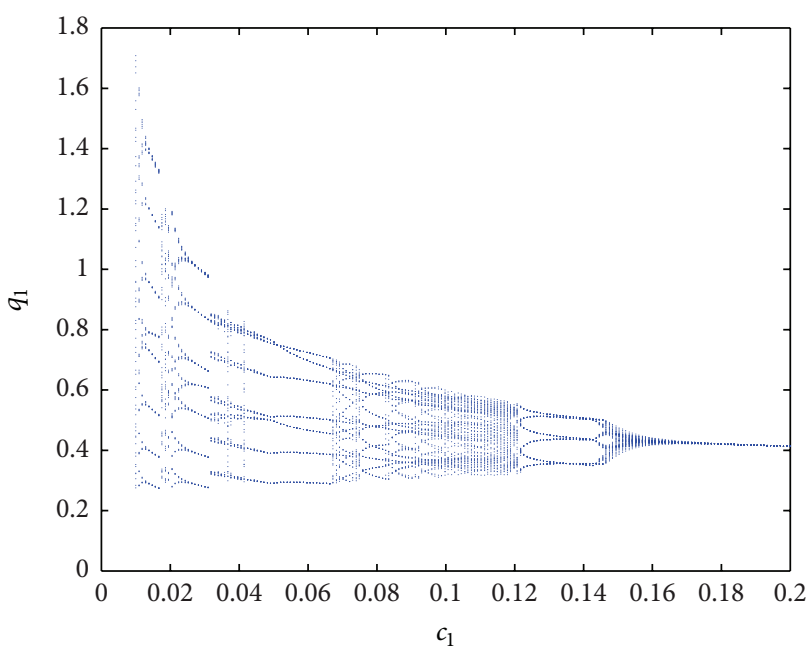

FIGURE 1: Bifurcation diagram with respect to parameter $c_{1}$ against variable $q_{1}$ with 500 iterations of map (8) for $v_{1}=v_{2}=0.5, c_{2}=2$.

\section{Numerical Simulations}

In this section, numerical simulation results corresponding to model (8) are presented. Bifurcation diagrams and phase portraits with respect to different parameters are used to show complex dynamical behaviors of the duopoly model.

Figure 1 presents the bifurcation diagram of system (8) with respect to parameter $c_{1}$ (per unit cost of firm 1) against variable $q_{1}$ for $v_{1}=v_{2}=0.5, c_{2}=2$. It is seen that the system is in periodic state for $c_{1}>0.18$. As $c_{1}$ decreases, periodic motion and chaotic motion occur alternatively. And the system is driven to chaos through quasiperiodic route. The main region where the system appears chaotic behavior is the range with $c_{1} \in[0.082,0.121]$. There exist many period orbits, such as period 7 orbit with $c_{1} \in[0.051,0.066]$ and period 8 orbit with $c_{1} \in[0.014,0.017]$, in model (8). For $c_{1}>0.18$, the stable output of firm 1 decreases with per unit cost $c_{1}$ increasing, which is consistent with the fact that the comparative superiority of firm 1 decreases as per unit cost $c_{1}$ increasing.

Now, set $v_{2}=0.7, c_{1}=0.14$, and $c_{2}=2$. It follows from (17) that $v_{1}^{*} \approx 0.2958$. Figure 2 shows the bifurcation diagram of map (8) with respect to parameter $v_{1}$. At $v_{1}^{*} \approx 0.2958$, a Neimark-Sacker bifurcation occurs. Nash equilibrium $E_{2}^{*}$ is locally stable for $v_{1}<0.2985$ and losses its stability for $v_{1}>$ 0.2985 . The system evolves from Nash equilibrium $E_{2}^{*}$ into chaos with parameter $v_{1}$ (weight on firm 1's reaction function) increasing, through the mechanism of quasiperiodic route.

Figure 3 depicts the trajectories of outputs of firm 1 and firm 2 in the phase space $\left(q_{1}, q_{2}\right)$ for $v_{1}=0.5, v_{2}=0.5$, $c_{2}=2$, and the initial point $(0.4,0.4)$. The red point is Nash equilibrium. A periodic attractor with $c_{1}=0.13$ is shown in Figure 3(b), while a quasiperiodic attractor with $c_{1}=0.12$ is shown in Figure 3(c). For $c_{1}=0.19$, the outputs of firm 1 and firm 2 converge to the Nash equilibrium, which is shown in Figure 3(a).

Figure 4 depicts the trajectories of outputs of firm 1 and firm 2 in the phase space $\left(q_{1}, q_{2}\right)$ for $v_{2}=0.7, c_{1}=0.14$, 


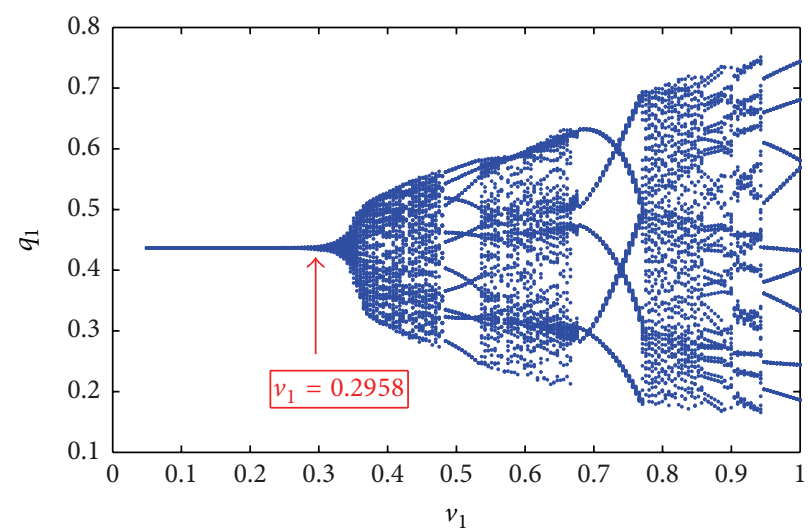

FIGURE 2: Bifurcation diagram with respect to parameter $v_{1}$ against variable $q_{1}$ with 500 iterations of map $(8)$ for $v_{2}=0.7, c_{1}=0.14, c_{2}=2$.

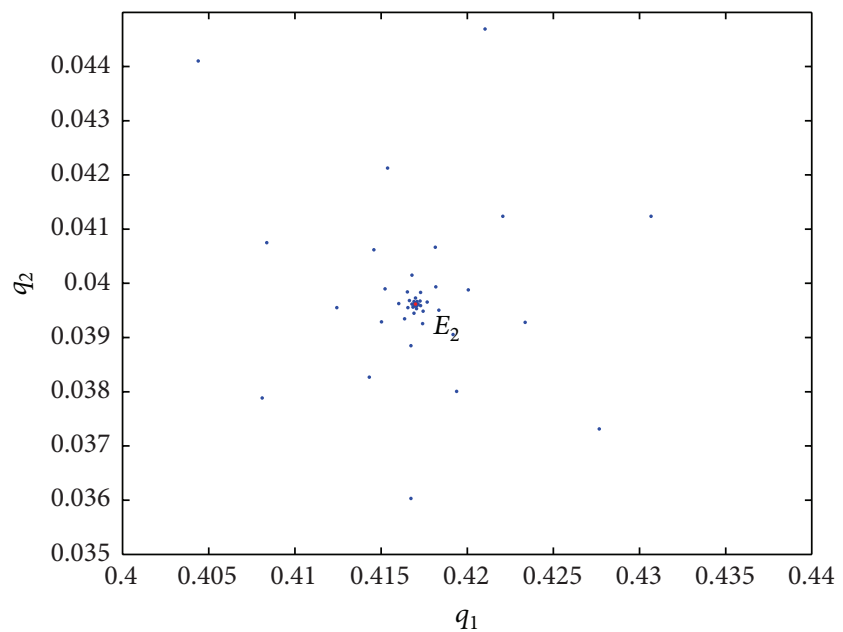

(a)

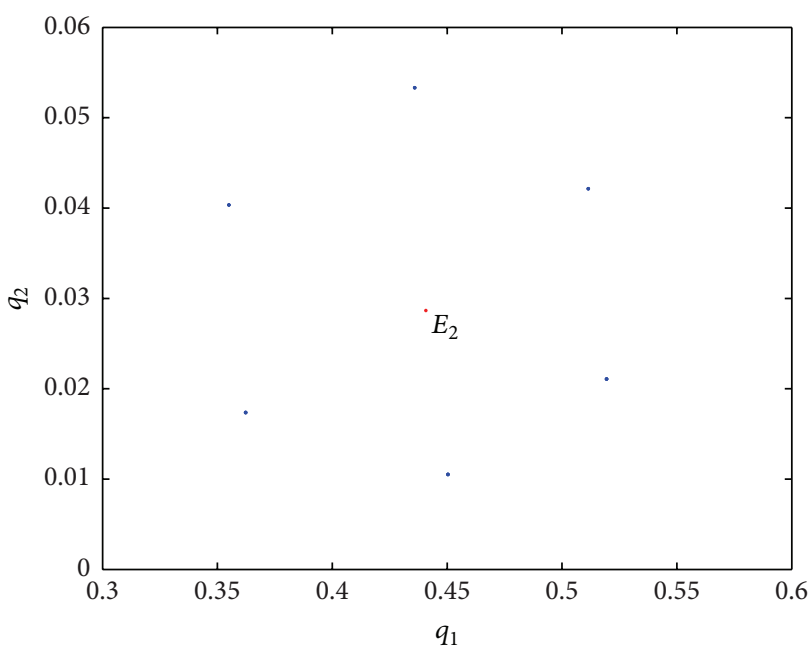

(b)

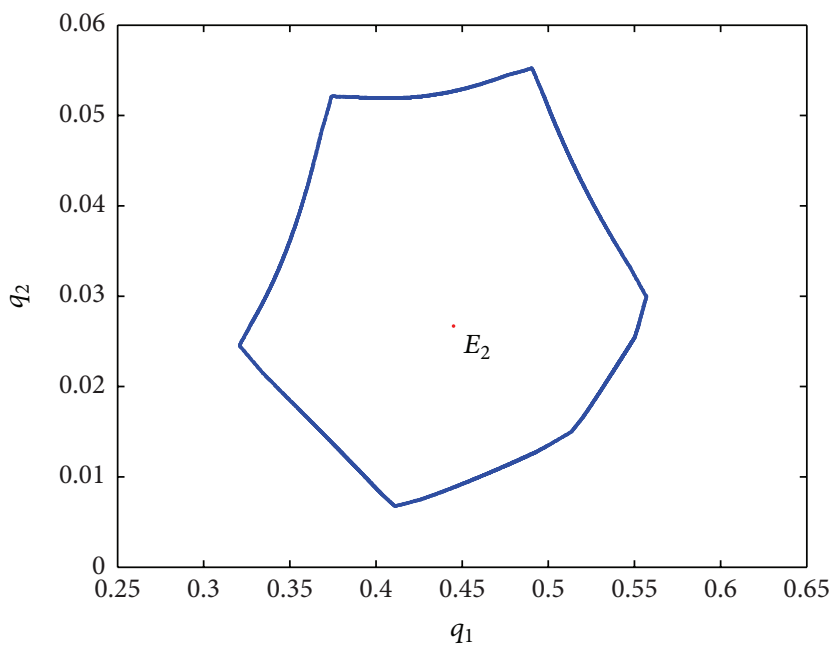

(c)

FIGURE 3: (a) Phase portrait of map (8) for $v_{1}=0.5, v_{2}=0.5, c_{1}=0.19, c_{2}=2$. (b) Phase portrait of map (8) for $v_{1}=0.5, v_{2}=0.5, c_{1}=$ $0.13, c_{2}=2$. (c) Phase portrait of map (8) for $v_{1}=0.5, v_{2}=0.5, c_{1}=0.12, c_{2}=2$. 


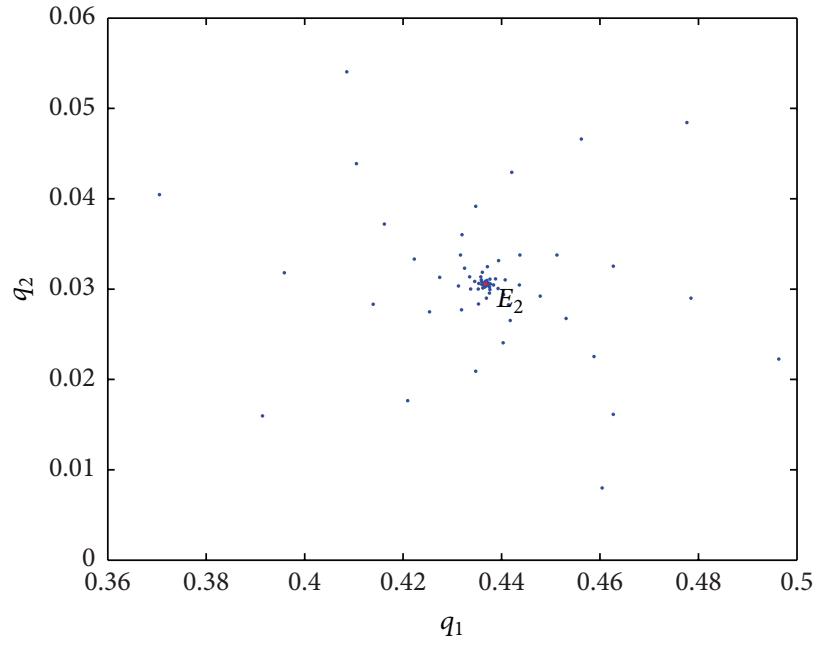

(a)

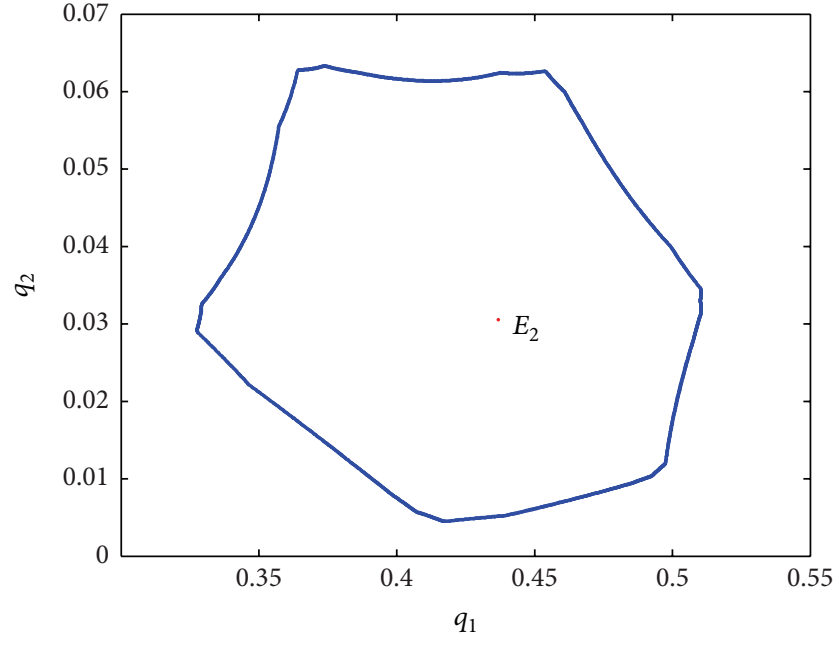

(b)

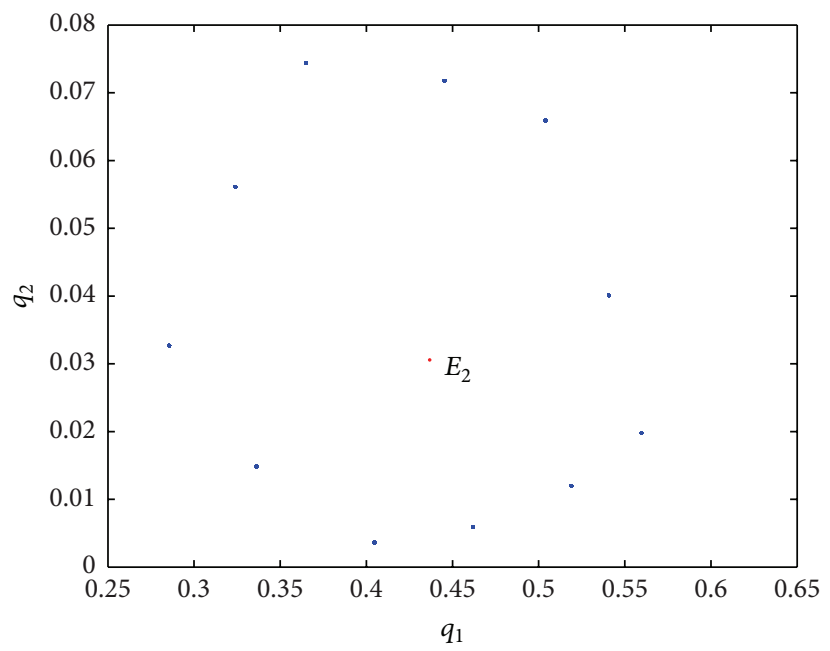

(c)

Figure 4: (a) Phase portrait of map (8) for $v_{1}=0.3, v_{2}=0.7, c_{1}=0.14, c_{2}=2$. (b) Phase portrait of map (8) for $v_{1}=0.37, v_{2}=0.7, c_{1}=$ $0.14, c_{2}=2$. (c) Phase portrait of map (8) for $v_{1}=0.48, v_{2}=0.7, c_{1}=0.14, c_{2}=2$.

$c_{2}=2$, and the initial point $(0.4,0.4)$. The red point is Nash equilibrium. For $v_{1}=0.3$, the outputs of firm 1 and firm 2 converge to the Nash equilibrium, which is shown in Figure 4(a). Figure 4(b) shows a quasiperiodic attractor with $v_{1}=0.37$ and Figure $4(\mathrm{c})$ shows a periodic attractor with $v_{1}=0.48$.

\section{Chaos Control in the Dynamic Output System}

Any firm does not want to adjust its outputs too frequently and largely. So it is important for firms to control their outputs to a stable process. Chaos control has been studied by many researchers since chaos has been found in economy $[6,13-$ 17]. In DFC (delayed feedback control) method [19], the most common control function is

$$
u_{t}=K(q(t)-q(t-1)) \text {. }
$$

We consider the case that only firm 1 adopts control function to make the system stable, while firm 2 does not realize that it will generate chaos in the future on the condition that firm 1 does not take any measure to prevent this case. Then, system (8) can be rewritten as

$$
\begin{aligned}
& q_{1}(t+1)=\left(1-v_{1}\right) * q_{1}(t)+v_{1} * q_{1}\left(q_{2}\right)+u_{1, t}, \\
& q_{2}(t+1)=\left(1-v_{2}\right) * q_{2}(t)+v_{2} * q_{2}\left(q_{1}\right),
\end{aligned}
$$

where $u_{1, t}=K_{1}\left(q_{1}(t)-q_{1}(t-1)\right)$.

To examine the effects of the control function, we compare the output process of firm 1 before and after adding the control function. Set $v_{1}=0.85, v_{2}=0.7, c_{1}=0.2$, and $c_{2}=2$ in model (8), which may exhibit chaos. The bifurcation diagram with respect to the control parameter $K_{1}$ is given in Figure 5. The system is stable for $K_{1}<-0.22$. For $K_{1}=-0.3$, the outputs processes of firm 1 before and after using control function are shown in Figure 6. It is seen that the control function effectively leads the outputs to a stable state. 


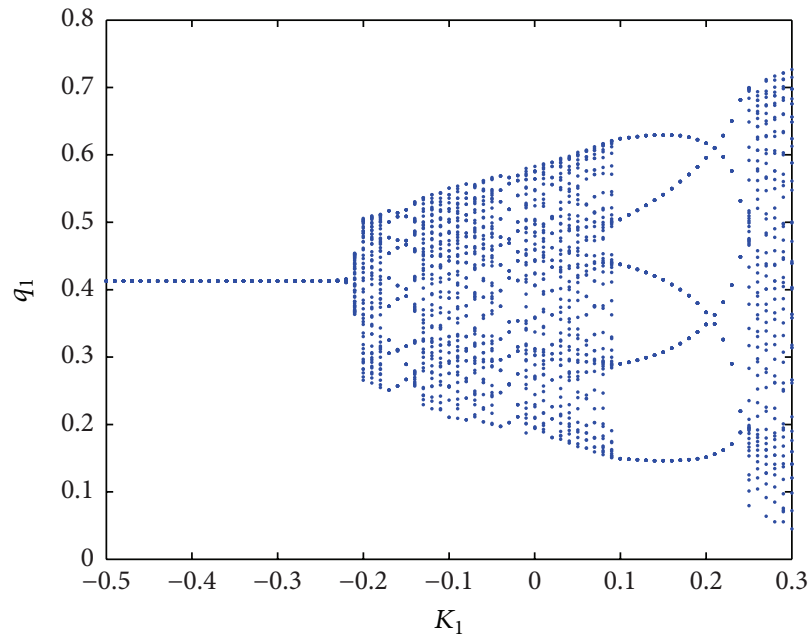

FIGURE 5: Bifurcation diagram with respect to parameter $K_{1}$ against variable $q_{1}$ with 500 iterations of map (19) for $v_{1}=0.85, v_{2}=0.7, c_{1}=$ $0.2, c_{2}=2$.

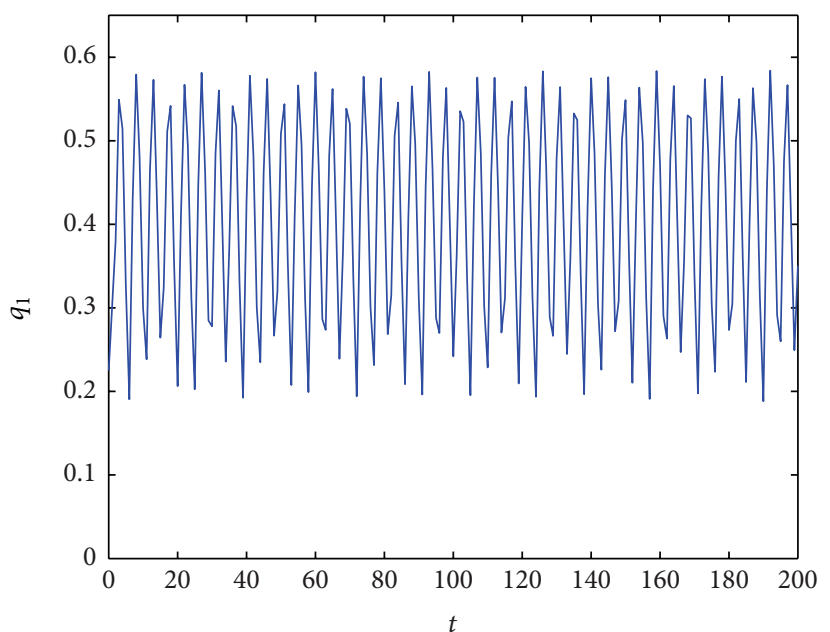

(a)

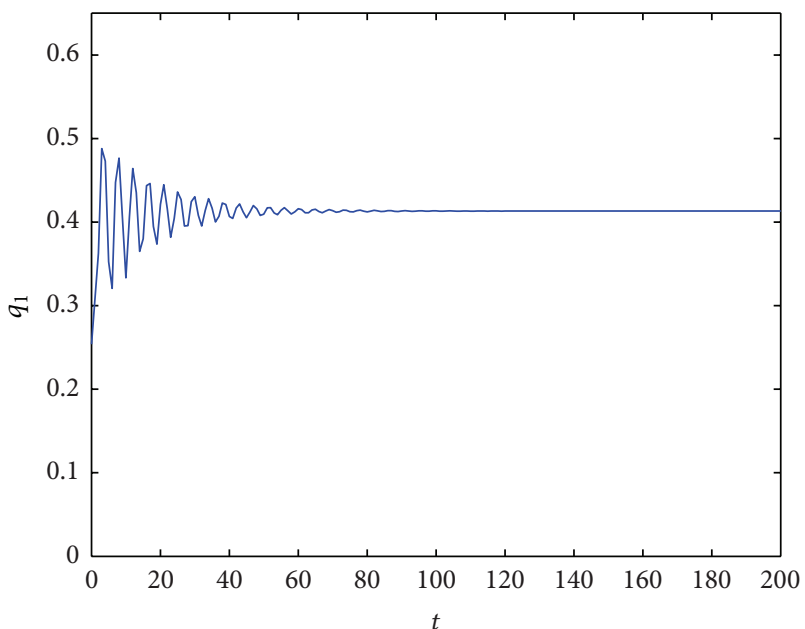

(b)

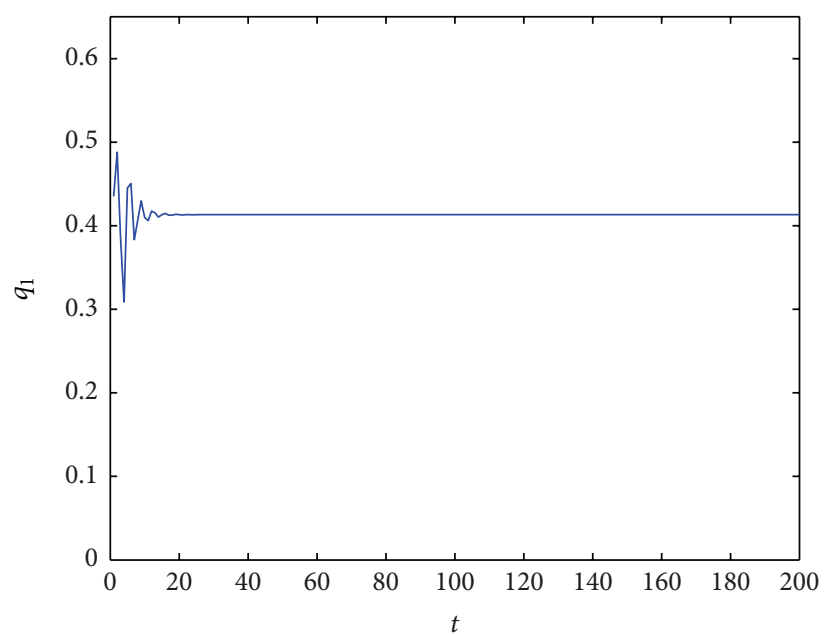

(c)

Figure 6: (a) Time series of output of firm 1 before using control function. (b) Time series of output of firm 1 after only firm 1 uses control function. (c) Time series of output of firm 1 after both firms use control function. 
Now, consider the case that both firms realize that they will generate chaos in the future if they do not take any measure to control it. Therefore, both firms use control function to stabilize their outputs. Then, system (8) can be rewritten as

$$
\begin{aligned}
& q_{1}(t+1)=\left(1-v_{1}\right) * q_{1}(t)+v_{1} * q_{1}\left(q_{2}\right)+u_{1, t}, \\
& q_{2}(t+1)=\left(1-v_{2}\right) * q_{2}(t)+v_{2} * q_{2}\left(q_{1}\right)+u_{2, t}
\end{aligned}
$$

where $u_{1, t}=K_{1}\left(q_{1}(t)-q_{1}(t-1)\right)$ and $u_{2, t}=K_{2}\left(q_{2}(t)-q_{2}(t-1)\right)$. The outputs of firm 1 are shown in Figure 6(c) for $K_{1}=-0.3$ and $K_{2}=-0.3$. By comparing Figure 6(b) with Figure 6(c), it is convenient to conclude that the effect of both firms taking control method is better than that of single firm taking control method.

\section{Conclusion}

In this paper, we have investigated a Cournot duopoly model where both the players decide their outputs weighting on their own previous outputs and the optimal outputs on the condition that their rival produces as their previous step. The Nash equilibrium and its local stability were analyzed. The numerical simulations show that the changes of marginal cost $c_{1}$ and weight factor $v_{1}$ may lead the Nash equilibrium to be unstable and the system into chaotic state. The system can quickly arrive at the Nash equilibrium by taking DFC method with a suitable controlling parameter. The effect of both firms taking control method is better than that of single firm taking control method.

In view of the fact that firms may not produce any goods if they suffer losses, it is needed to take firms' profits into consideration in modeling the outputs of firms. This problem will be investigated in our future research.

\section{Competing Interests}

The authors declare that they have no competing interests.

\section{Acknowledgments}

This work was supported by the National Natural Science Foundation of China (Grant no. 71571007), the State Key Program of National Natural Science Foundation of China (Grant no. 71333014), and the Aeronautical Science Foundation of China (Grant no. 2012ZG51079).

\section{References}

[1] A. Cournot, Recherces sur les Principes Mathématiques de la Théorie des Richesses, Hachette, Paris, France, 1838.

[2] H. N. Agiza and A. A. Elsadany, "Nonlinear dynamics in the Cournot duopoly game with heterogeneous players," Physica A: Statistical Mechanics and Its Applications, vol. 320, pp. 512-524, 2003.

[3] H. N. Agiza and A. A. Elsadany, "Chaotic dynamics in nonlinear duopoly game with heterogeneous players," Applied Mathematics and Computation, vol. 149, no. 3, pp. 843-860, 2004.
[4] J. Ma and W. Ji, "Chaos control on the repeated game model in electric power duopoly," International Journal of Computer Mathematics, vol. 85, no. 6, pp. 961-967, 2008.

[5] G. Sarafopoulos, "Chaotic effect of linear marginal cost in nonlinear duopoly game with heterogeneous players," Journal of Engineering Science and Technology Review, vol. 8, no. 1, pp. 25-29, 2015.

[6] J. Du, T. Huang, Z. Sheng, and H. Zhang, "A new method to control chaos in an economic system," Applied Mathematics and Computation, vol. 217, no. 6, pp. 2370-2380, 2010.

[7] H. Tu and J. Ma, "Complexity and control of a cournot duopoly game in exploitation of a renewable resource with bounded rationality players," WSEAS Transactions on Mathematics, vol. 12, no. 6, pp. 670-680, 2013.

[8] A. A. Elsadany and A. E. Matouk, "Dynamic Cournot duopoly game with delay," Journal of Complex Systems, vol. 2014, Article ID 384843, 7 pages, 2014.

[9] L. Yali, "Analysis of duopoly output game with different decision making rule," Management Science and Engineering, vol. 9, pp. 19-24, 2014.

[10] A. M. A. El-Sayed, A. A. Elsadany, and A. M. Awad, "Chaotic dynamics and synchronization of cournot duopoly game with a logarithmic demand function," Applied Mathematics and Information Sciences, vol. 9, no. 6, pp. 3083-3094, 2015.

[11] T. Puu, "Chaos in duopoly pricing," Chaos, Solitons and Fractals, vol. 1, no. 6, pp. 573-581, 1991.

[12] M. Kopel, "Simple and complex adjustment dynamics in Cournot duopoly models," Chaos, Solitons and Fractals, vol. 7, no. 12, pp. 2031-2048, 1996.

[13] L. Chen and G. Chen, "Controlling chaos in an economic model," Physica A: Statistical Mechanics and Its Applications, vol. 374, no. 1, pp. 349-358, 2007.

[14] W. Wu, Z. Chen, and W. H. Ip, "Complex nonlinear dynamics and controlling chaos in a Cournot duopoly economic model," Nonlinear Analysis: Real World Applications, vol. 11, no. 5, pp. 4363-4377, 2010.

[15] R. Hu and Q. Chen, "Chaotic dynamics and chaos control of cournot model with heterogenous players," Advances in Intelligent and Soft Computing, vol. 110, pp. 549-557, 2011.

[16] A. A. Elsadany, "A dynamic Cournot duopoly model with different strategies," Journal of the Egyptian Mathematical Society, vol. 23, no. 1, pp. 56-61, 2015.

[17] H. N. Agiza, A. A. Elsadany, and M. M. El-Dessoky, "On a new cournot duopoly game," Journal of Chaos, vol. 2013, Article ID 487803, 5 pages, 2013.

[18] Y. A. Kuznetsov, Elements of Applied Bifurcation Theory, vol. 112 of Applied Mathematical Sciences, Springer, New York, NY, USA, 1995.

[19] K. Pyragas, "Continuous control of chaos by self-controlling feedback," Physics Letters A, vol. 170, no. 6, pp. 421-428, 1992. 


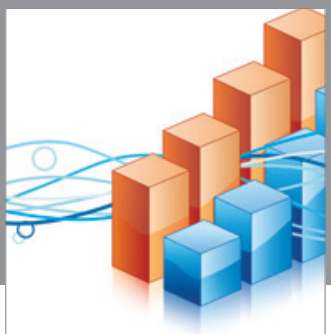

Advances in

Operations Research

vatem alat4

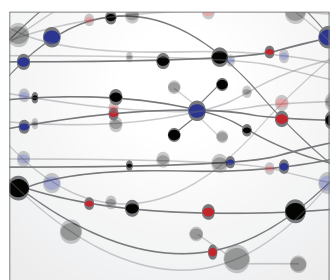

\section{The Scientific} World Journal
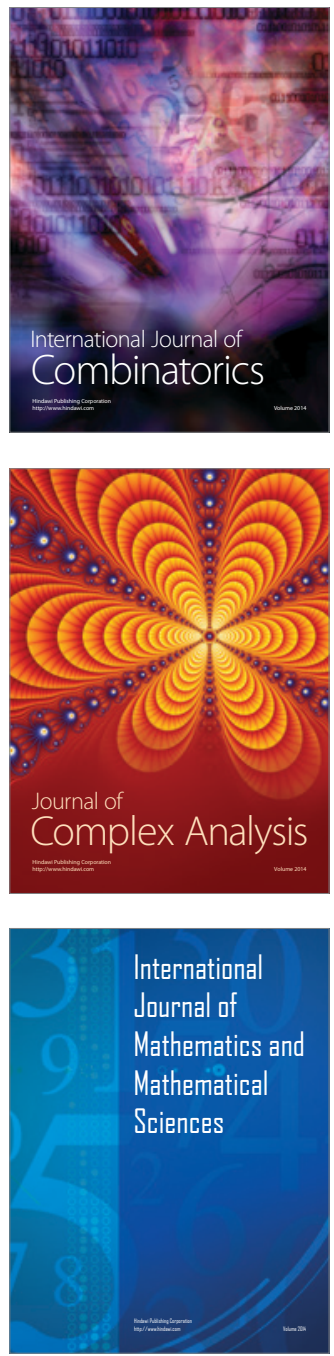
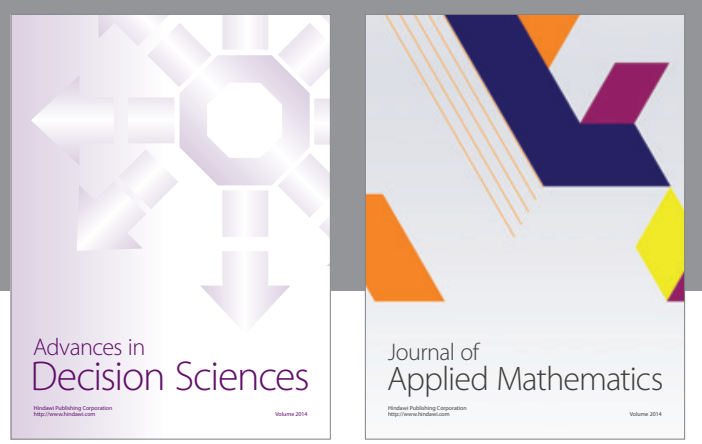

Algebra

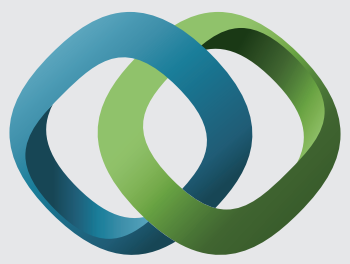

\section{Hindawi}

Submit your manuscripts at

http://www.hindawi.com
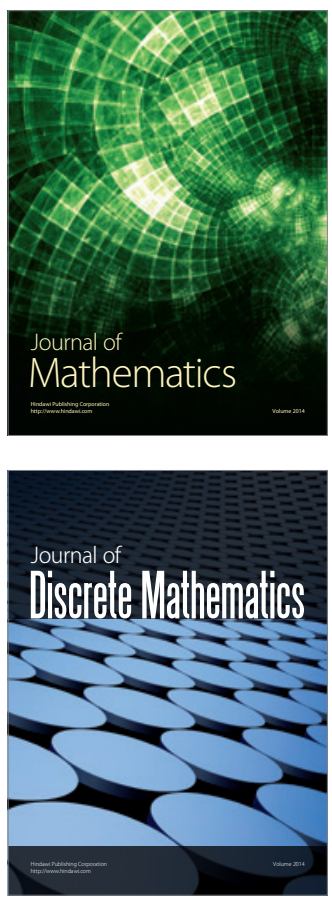

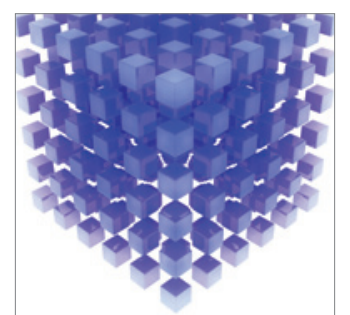

Mathematical Problems in Engineering
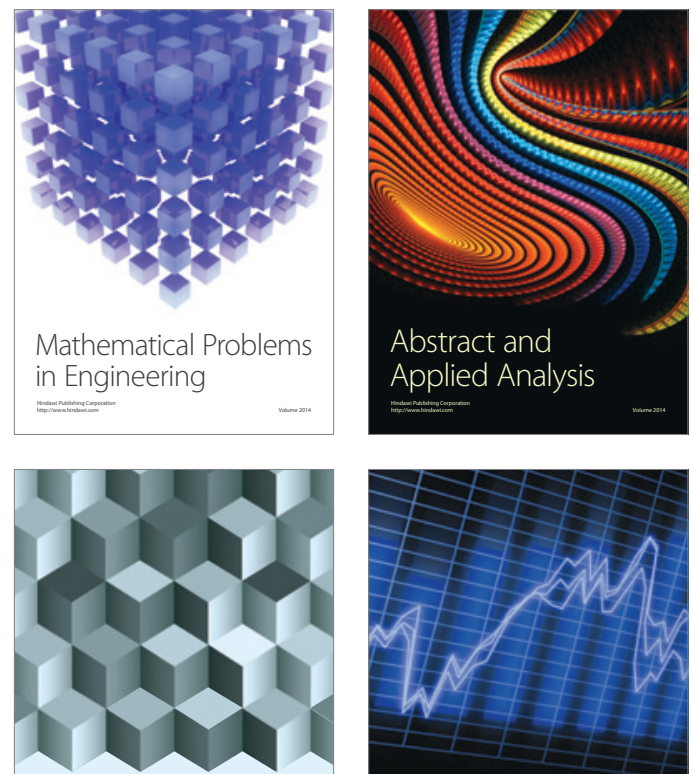

Journal of

Function Spaces

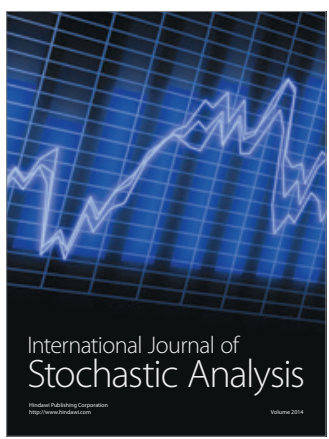

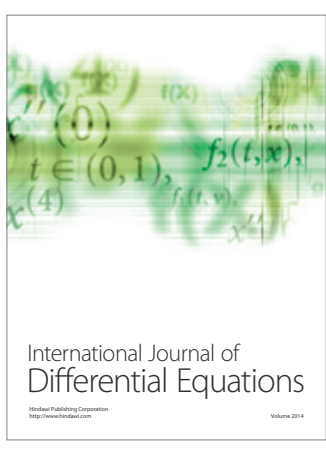
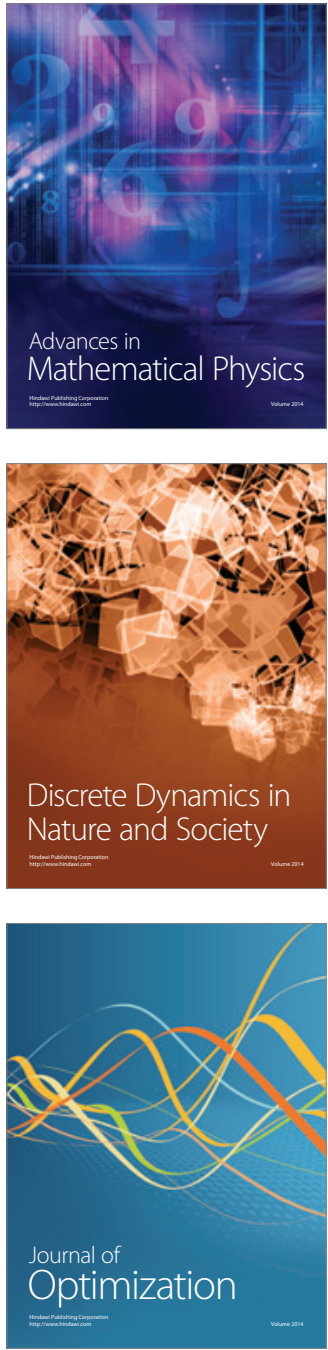